\title{
Sustaining Tourism Development in Protected Areas. A Case of Kinabalu Park
}

\author{
Hong Ching, Goh and Mariney Mohd Yusoff
}

\begin{abstract}
Sustainable tourism emerges as more responsible form of tourism seeks to minimize the undesirable impacts of tourism development at destination level. Specifically, its presence in nature-based tourism destinations provides financial revenue for nature conservation through maintaining high quality visitor experience. Kinabalu Park is the first World Heritage Site of Malaysia. Since its establishment in 1964, the park has been a popular tourism destination in the country and in the region. The significant and increasing inflow of visitors to the park has raised the concern over its management in meeting the visitor expectation without compromising with its conservation objective, which is the key role of a protected area. This paper intends to highlight the park management in responding to its dual roles in conserving nature and meeting visitor satisfaction, thereby meeting some principles of sustainable tourism.
\end{abstract}

Index Terms - Sustainable tourism, nature conservation, visitor satisfaction, park management

\section{INTRODUCTION}

Tourism and protected areas have been intimately related for centuries with notable implications since, or perhaps even before, the establishment of Yellowstone in 1872. Tourism has been much depending on the outstanding natural landscape in protected areas for its survival and to operate. In 2004, the segment of tourism in natural areas grew three times faster than the entire tourism industry as a whole [1]. This growth is believed to be also resulted from the increase in the number of protected areas worldwide. According to IUCN and UNEP WCMC (2003) [2], the number of protected areas worldwide had grown from 1,000 in 1960s to over 100,000 in 2002. A protected area is defined as '... An area of land and/or sea especially dedicated to the protection and maintenance of biological diversity, and of natural and associated cultural resources, and managed through legal or other effective means' [3]. Based on the principles of sustainable tourism, tourism is able to support these roles of parks.

The concept of sustainable tourism was introduced after the Rio Earth Summit in 1992, alongside with the mainstream sustainable development. According to World Tourism Organization (2004) [4], its development guidelines and practice are applicable to all forms of tourism in all types of destinations including mass tourism and the various niche tourism segments. Its sustainability principles are built on the three pillars known as environmental, economic and

Department of Geography, Universiti Malaya socio-cultural aspects of tourism development. Specifically, in meeting its socio-economic principles, tourism is required to channel financial support to help in conserving natural heritages and biodiversity and to use the environmental resources at optimum level. Nevertheless, a high level of tourist satisfaction must be maintained by providing a meaningful experience to tourists.

In protected areas, the financial revenue generated from tourism activities in parks can be channeled into areas of conservation. This includes the daily maintenance and management related to the protection of parks, research activities and staff training. Tourism impact management is also crucial to ensure that the negative bio-physical impacts of tourism are kept to the minimum. At the same time, to enhance the favorable socio-economic impact of tourism, high level of satisfaction and experience among visitors must be maintained. Visitor satisfaction depends upon the qualities of activities and facilities available in a park. As visitor satisfaction is very much depending on their expectation closely associated with their socio-demographic and geographical background, a study of tourism demand is crucial for park management to understand the diversified expectations of visitors. Apart from the financial benefits, providing high quality educational experience to park visitors also contributes to conservation objectives at large. It contributes significantly in educating and creating public awareness about environment importance and protection. Thus, tourism and natural environment may achieve a win-win situation.

\section{NATURE Of GoOdS AND PRIVATIZATION}

A public good is distinguished from a private good based on two characteristics, i.e., excludability and divisibility. Excludability is the possibility to exclude people who have not paid for a good or service from consuming it. Divisibility refers to situation where consumption by someone prevents simultaneous consumption by others. A public good refers to any good or service whose provision is non-excludable and non-divisible, meaning that everyone can enjoy the good. Besides, it is still available to the general public once it is provided to an individual. In contrast, a private good is excludable and divisible. This means one can be excluded from enjoying a good, and it is no longer available to others once it is provided to a consumer.

Understanding the nature of goods in protected areas is important as it is recognized that private and public goods and services require different government arrangements [5][6]. Specifically, it helps in guiding the park management 
to secure funding to sustain nature conservation activities. Watershed and natural habitat protection are some of the public goods present in protected areas. These public goods usually require government funding as it is not traded in markets thus showing no market value. On the other hand, private goods have high potential for commercialization. Tourism activities and facilities are regarded as private goods Visitors can be charged for using the tourism resources and facilities or participating in tourism activities offered in protected areas. Some of the examples are user fees to interpretation centre, canopy walkways, and charges on lodges as well as catering services. Therefore, tourism to protected areas provides the economic contribution to support nature conservation.

Until today, many protected areas worldwide are still managed by public sector. Despite of this tradition, public sector has been criticised for its lack of capability to deliver tourism expected benefits such as satisfactory tourism services and facilities in meeting tourist satisfaction thereby stimulating employment creation and regional development at large. Its heavy bureaucratic structure has limited it from responding quickly to market change, which is very crucial in tourism development [7]. These short shortcomings in tourism performances have paved the road for privatization program to take place in protected areas.

Privatisation can be broadly defined as 'the process of change, in which the private sector takes responsibility for activities that were formerly controlled exclusively by the public sector. This many include the transfer of ownership of productive assets from the public to the private sector or may simply imply that 'space' is created in which the private sector can operate' [8]. The involvement of private sector has been advocated for its ability in managing tourism goods and services in protected areas mainly due to its profit-driven nature. According to the property right theory, the market generates demand to prevent corporate management from dissipating value through wage rewards or slack attention [9]. Tourism demand in free market requires the tourism enterprises to be sufficient enough in producing a residual reward by meeting tourist demand thus satisfaction, so that they could survive in the market [9]. Furthermore, the potential profits generated through tourism services is an 'incentive' to private sector for them to offer high standard of tourism services in meeting the tourist expectation.

Giving this assumption, it is foreseen that with such arrangement, protected area will not only be able to improve the quality of its tourism services but the program will also enable the public sector to fully utilize its available human and financial resources to secure public goods and services, i.e., nature conservation activities. With the diversified management structure, a protected area will able to provide public and private goods and services while receiving a viable financial return to sustain its long term existence. In fact, the introduction of privatisation has seen some economic benefits to protected areas such as in South African National Parks (SANParks) and in the USA [10]. The private sector often involves itself as tourism service provider such as accommodation, catering, tour operations, waste collection, and information provision in the form of concessionaires. In South Africa, it is expected that the tourism concessions in SANParks are to generate profits of USD35-53million over the next 20 years together with the creation of 700-800 new jobs.

On the other hand, the introduction of privatisation raises concerns in the new management structure. First pertains to the ability of public sector to cope with new responsibilities after the introduction of privatisation. As a change in institutional arrangement is required for privatisation to take place, the shift of roles from public to private sector also involves a change in perception in management [11]. Some existing organisation may experience difficulty to conceive a new perception on its new roles in management. For instance, the park authority in protected areas may not able to conceptualize and implement a new range of goods and services suitable to nature conservation purpose. Second, concern is raised over the status of private sector involvement especially when they are granted with the monopoly privilege. The single provider in the market has a great deal of power over buyers. Since they do not face price pressure from competitors, monopolists can raise prices thus increasing revenues [12]. Because of this, they are capable of acting against public interest especially in protected areas, despite these areas are designated mainly for the protection of natural heritage and biodiversity- for the generational public welfare

\section{KINABALU PARK AN OVERVIEW}

Established in 1964, Kinabalu Park is one of the most visited parks in Malaysia. The park is located in Sabah in East Malaysia and covers an area of 75,370ha. It is a Type II protected area according to the IUCN category system. Kinabalu Park has been well-known internationally for its flora diversity and also a prominent site for climbing activities especially in the region of South East Asia with its splendid mountainous landscape.

In terms of its biodiversity significance, Kinabalu Park gains several recognitions which include its designation as Malaysia's Centres of Plant Diversity and a Centre of Plant Diversity for Southeast Asia [13]. It has also been identified as one of the world's 13 hotspots for biodiversity and one of the 234 sites designed as the primary centres of plant diversity in the world. The park has also gained the recognition as World Heritage Site in 2000 when it meets the selection criteria ii and iv [14][15]. On the other hand, Mount Kinabalu which sours up 4,095.2m a.s.1., is the focus in the park which attracts thousands of climbers and visitors to the park every year. The number of visitor arrivals rose from 829 in 1965 to more than 434,000 in 2005. Of this, foreign visitors made up $22 \%$ of the total arrivals in 2005 . The significance in number of visitor arrivals also marks the substantial revenue generated through tourism activities in the park. In 2005, Kinabalu Park was the most revenue generating park within Sabah Parks system which consists of a total of 9 parks $(53 \%$ or a total of approximately RM5.5million). Of the total revenue collected in Kinabalu Park, nearly $50 \%$ was contributed by climbing activities (climbing permits and certificates).

In coping with the rising number of visitor arrivals and 
expectation on tourism facilities, a privatization program was introduced to take over the management of accommodation and catering facilities in Kinabalu Park in 1998. While the management of facilities were privatised, all tourism activities were still managed by Sabah Parks. The program was introduced to improve the quality of tourism facilities in Kinabalu Park and to reduce the administrative, manpower as well as financial burden of Sabah Parks thereby enabling the organisation to focus on conservation activities [16][11].

This paper intends to reveal how the new management had responded to conserving nature and also meeting tourism demand in the park. In meeting this objective, a study was carried out in Kinabalu Park in 2006 then again in 2009. This includes conducting interviews and questionnaire survey. Park staff and personnel were interviewed and park visitor satisfaction level was identified through questionnaire survey. In determining the efforts on conservation, the significance of tourism revenue, breakdown of expenses, budget allocation for conservation and tourism activities, staff training and research activities, existence of tourism impact management and monitoring system were used as indicators. Level of visitor satisfaction was determined using indicators such as satisfaction level with the quality and price of tourism facilities and activities offered in the park. Existence of visitor database and tourism demand studies were also used for the discussion on visitor satisfaction.

\section{Conserving Nature And Meeting Tourism DEMAND IN KINABALU PARK- THE REALITY}

Because The analysis results of the budget allocation to Kinabalu Park indicated that the park management has not shift its focus to nature conservation after the privatization program [11]. Tourism income generated in Kinabalu Park was substantial. As at 2005, a total of RM5.5million was collected from tourism activities at the destination. Nonetheless, the major part of the allocated budget was still used for tourism-related development. In $2005,47 \%$ of its budget was used for tourism-related development instead of investing into research and education activities and for staff training, which are the important components of nature conservation. In addition, despite of the privatisation of tourism facilities, Sabah Parks remained as the park authority but failed to set up monitoring system to evaluate the ecological impacts of tourism, after being released from the administration and manpower burden in managing tourism facilities. This is especially crucial along the summit trail, in which the trail has been ascended by more than $20 \%$ of its total number of visitor arrival every year and nothing that the park has been the home to a number of endemic flora species. Although Sabah Parks has introduced several tools such as creating honey pots, dispersing use, managing carrying capacity to control the human impacts in the park, the effectiveness of these tools in regulating tourism impacts is unknown.

The budget allocation for research and education activities was still low and there is no indication of an increase in 2005. In addition, there was no clear indication of an increased budget to support staff training after the privatisation program and consistency in budget allocation for staff training. An analysis of the overall budget allocation for staff training within Sabah Park system also reveals that about $50 \%$ of the total budget was allocated for staff at Sabah Parks HQ instead of benefiting the staff at site.

As for visitor satisfaction, the overall level of visitor satisfaction based on the survey in 2006 was above average. In particular, many repeat visitors expressed satisfaction over the improvement in the quality of accommodation facilities after the introduction of the program. However, the knowledge-based aspects in tourism activities offered by Sabah Parks would require substantial improvement. This includes the nature guiding quality in terms of communication skill, ability to answer questions, English literacy and information provided. Similar feedbacks were obtained in evaluating the satisfaction level on mountain guiding which was provided by the local folks, licensed by Sabah Parks.

Despite of the mixed results with favour on private operation on accommodation facilities in 2006, visitor satisfaction survey conducted in 2009 revealed a sharp declining level of satisfaction among the visitors to Kinabalu Park with the major critique on the price of accommodation. The price of accommodation was increased skyrocket since 2007 with the introduction of dual tiered system stratifying domestic and foreign guests (RM30 and RM46 respectively). In less than 3 years, the price was further increased striking up to RM100 (domestic guests) and RM120 (foreign guests) for a bed in dormitories at Park HQ. Lodges which can accommodate 6 persons and come with full board meals, price up to RM8,000 per night at Park HQ. Furthermore, climbing packages were introduced at RM501 at dormitory for climbers for a 3-day 2-night in the park (1 night at Laban Rata and 1 night at Park HQ). The domestic visitors had complaint over the affordability of enjoying the national iconic treasure where they had no choice but are forced to take up the package which is expensive for the locals especially students. In the past, climbers had a choice to bring their simple food ascending the mountain thus saving some cost. In addition, the dual tiered pricing system had marginalized the opportunities of domestic visitors to participate in mountain climbing. As the accommodation availability was set at 160 persons at Laban Rata ${ }^{1}$ and the climb required a night stay at Laban Rata, many domestic visitors complaint that it was extremely difficult to make bookings because the private operator favoured bookings made by foreign visitors for much higher profit margin

\section{DISCUSSION}

\section{A. Public and Private Goods versus Publics and Private Sector}

Tourism activities and facilities provided by Sabah parks and the private sector are some of the private goods in Kinabalu Park. They are provided to the park visitors at a fee. By imposing a user fee, visitors who do not pay will not enjoy

${ }^{1}$ Laban Rata $(3,314 \mathrm{~m}$ a.s.1.) is the last stop on the summit trail equipped with restaurant and accommodation facilities 
the activities and facilities. These goods generate direct financial income to the park. In contrast, nature conservation such as staff training, research activities are public goods. Scientific and historical information of the park can be shared infinitely without diminishing their value for everyone who shares it. Similarly, training provided to the staff is shared by everyone without losing its quality. In Kinabalu Park, Sabah Parks was unable to indicate better financial emphasis to support these components of nature conservation. In dealing with private goods, there was no feedback obtained by Sabah Parks to understand the expectation and experience of the park visitors. Lack of this understanding thwarted its ability to tackle the expectation of park visitors especially in terms of the increasing demand on educational information at interpretation centre and guiding services. This conforms to the relatively less capability of public sector in managing private goods.

On the other hand, the private sector that manages the accommodation facilities was able to meet the visitor expectation in the early years of privatisation with the notable improvement in terms of quality of facilities and services. Driven by the profit-nature, it obtained feedback from the resort guests to quickly respond to the market expectation. This conforms to the general consumption that private sector is relatively more capable in providing private goods than the public sector. However, the monopoly control in providing the accommodation and eateries facilities especially at Laban Rata, demonstrates the risk of having private sector dominating the business as sole player in the market. The lack of economic competition enables the private sector to create artificial shortages (e.g., bookings by domestic climbers and to actually offer only the 3-day 2-night package) as well as in raising accommodation rate to increase their profit margin. The monopoly status of private sector had apparently thwarted the role of Kinabalu Park for public enjoyment. The introduction of privatisation which comes with a concession of 30 years also discloses the difficulty in controlling the private sector especially in the case where they enjoy the monopoly status.

\section{B. Tourism for Whose Benefits}

National Park as Type II protected areas according to IUCN Protected Area Category System are areas designated to serve both nature conservation and recreation objectives. Nonetheless, as stated by Eagles and McCool (2002:22) [17] that 'a general concept underlying nature conservation is that of higher ecological integrity in the absence of human interference'. Hence, it is important to implement tourism impact management in order to ensure that nature conservation in Kinabalu Park is not compromised with its recreational/tourism functions [11]. Meanwhile, despite of the fact that tourism has been the inspiring factor behind the establishment of protected areas; nature conservation is still the key justification for the set up of protected areas. Furthermore, tourism holds no property but relies on nature environment (in this case) to operate and survive. Tourism in protected areas must able to support nature conservation so as to sustain its operation at the same time. Enhancing visitor experience in a park has positive influence on the revenue generated. If visitors do not respond positively about their experiences, very likely visitors will cease to come, and there will be no tourism' [18].

In Kinabalu Park, one of the objectives of introducing privatisation program was to foster tourism development by improving the quality of its tourism facilities thereby shifting Sabah Parks' obligation to solely focus on nature conservation in the park. However, while the reasons to advocate privatisation were justified, the threats were not identified and there was no strategies formulated in tackling the arising issues. Despite of the initial positive feedback pertaining to the management by private sector, the result was not sustainable. The monopoly status of the private sector would lead to two possibilities in tourism development in Kinabalu Park if there is no immediate action taken. Firstly, the visitor segmentation in Kinabalu Park would experience a change (which is actually gradually shaping) where only affordable and wealthy visitors can climb the mountain and stay in the park; and that Mount Kinabalu climbing would become an international activity for the enjoyment of foreigners who are generally more affordable to pay the fees rather than an leisure activity for its nationals. Secondly, Sabah Parks would experience a decrease of income generated through mountain climbing activities especially during the low season of foreign visitors because lesser locals could climb the mountain, which could have been used to support partly, if not entirely its nature conservation activities.

On the other hand, Sabah Parks, which has been released from managing the accommodation facilities, was unable to further enhance the financial allocation into activities such as staff training and research activities which are pre-requisite for conservation. Furthermore, the educational elements would need improvement to meet the rising expectation of park visitors. The absence of monitoring system also thwarted Sabah Parks' efforts to monitor and evaluate the long-term human impacts on the park ecosystem especially along the summit trail which is very ecological sensitive. Besides, evaluation of the effectiveness of the existing tourism impact management tools was made impossible without the monitoring system

\section{Some Application-Oriented Recommendations}

World heritage sites are recognised as models of effective management and conservation. Therefore, Kinabalu Park should demonstrate a good example of management especially in terms of nature conservation. Recommendations for Kinabalu Park focus on a higher investment into nature conservation activities especially in terms of staff training and research activities. Collaboration can be set up with the external institutions to improve management capacity and on knowledge-based development to enhance visitor experience. Long-term research collaboration can also be established with local universities to carry out necessary research. Apart from solving the problem regarding lack of skilled staff, this would also help in establishing a continuous training program for the staff by getting them to work with the experts from local universities. Park management should also shift its focus on mainly improving the quality of tourism infrastructure to enhancing human resource capacity, e.g., nature guides. In addition, a proper mechanism to obtain 
feedback from the visitors is essential for the park to continuous monitoring the dynamic expectations of park visitors.

\section{CONCLUSION}

To conclude, the case of Kinabalu Park demonstrates the significance of institutional arrangement in regulating tourism impacts in protected areas in meeting some principles of sustainable tourism. The key driver to successfully implementing sustainable principles of tourism at destination level relies on the institutions being assigned in the management. By analyzing the nature of goods and the nature of public and private sector, Kinabalu Park reveals first, the relatively inability of public sector in dealing with private goods and secondly, the better ability of private sector in managing private goods. Nonetheless, the monopoly status of the private sector has ruined the initial objective set for the introduction of privatisation in the park

\section{REFERENCES}

[1] WTO (2004) http://www.world-tourism.org/facts/tmt.html. Cited 16 Feb 2004.

[2] IUCN and UNEP WCMC (2003) 2003 United Nations List of Protected Areas (Compiled by Stuart Chape, Simon Blyth, Lucy Fish, Phillip Fox and Mark Spalding). IUCN, Gland and Cambridge, UNEP WCMC, Cambridge.

[3] IUCN and WCPA (2004) The IUCN management Categories Speaking a common language about protected areas (information paper). $7^{\text {th }}$ Meeting of the Conference of the Parties to the Convention on Biological Diversity (COP7), Kuala Lumpur, Malaysia 9-20 Feb $2004 . \quad$ http://www.iucn.org/themes/wcpa/pubs/pdfs /pacopcategories.pdf. Cited 23 June 2007.

[4] World Tourism Organisation (2004) WTO. Indicators of sustainable development for tourism destinations: A guidebook. World Tourism Organization, Madrid, 2004.

[5] A. James, K. J. Gaston and A. Balmford. Why private institutions alone will not do enough to protect biodiversity. Nature. 2000, 404:120.

[6] Gatzweiler F. W. Institutionalizing biodiversity conservation- the case of Ethiopian coffee forests. Conservation and Society. 2005, 3 (1):201-223.

[7] C. L. Jenkins. Tourism in developing countries: the privatization issue. In: Seaton, A.V. (ed) Tourism: The State of Art. Chichester: Wiley, pp.3-9. 1994.

[8] Carney D and Farrington J (1998) Natural Resource Management and Institutional Change. Routledge, London.

[9] P. Starr. The meaning of privatization. Yale Law and Policy Review 6 (1988): 6-41. Reprinted in Alfred Kahn and Sheila Kamerman (eds) Privatization and the Welfare State. Princeton University Press, 1989. http://www.princeton.

edu/ starr/articles/articles80-89/Starr-MeaningPrivatization-88.htm. Cited 30 Sept 2007.

[10] Font X, Cochrane J and Tapper R (2004) Tourism for protected area financing: Understanding tourism revenues for effective management plans, Leeds (UK): Leeds Metropolitan University. A report submitted to WWF.

[11] H. C. Goh. Sustainable Tourism and the influence of privatisation in protected area management. A case of Kinabalu Park, Malaysia. Ecology and Development Series 57, 2008.

[12] C. A. Dapken II. Microeconomics Demystified, McGraw Hill Publishers, California, 2006.

[13] UNESCO WHC (2007) World Heritage: Kinabalu Park http://whc.unesco.org/en/list/1012. Cited 20 Aug 2007.

[14] Sabah Parks (1998) Kinabalu Park: A world heritage site? Sabah Parks proposal submitted to the Sabah State Cabinet, unpublished paper, Kota Kinabalu, Sabah.

[15] UNESCO WHC (2006) New sites to be inscribed on UNESCO World Heritage List. http://whc.unesco.org/en/news/132. Cited 23 Mar 2006

[16] Ali L and Basintal P (1997) The Status and future directions of Sabah Parks in LESTARI Proceeding, 1997, Universiti Kebangsaan Malaysia, Selangor.
[17] Eagles P F J and McCool S F (2002) Tourism in national parks and protected areas. Planning and management. CABI Publishing, UK.

[18] Wall G (1996) Ecotourism: Change, impacts and opportunities. In: Miller J A and Malek-Zadeh E (eds) The ecotourism equation: measuring the Impacts. Bulletin Series: Yale School of Forestry and Environmental Studies number 99, Yale University, New Haven, Connecticut, pp108-177. 